Western University

Scholarship@Western

FIMS Publications

Information \& Media Studies (FIMS) Faculty

Winter 2016

\title{
The Paradox of Privacy: Revisiting a Core Library Value in an Age of Big Data and Linked Data
}

Grant D. Campbell

Western University

Scott Cowan

University of Windsor

Follow this and additional works at: https://ir.lib.uwo.ca/fimspub

Part of the Library and Information Science Commons

Citation of this paper:

Campbell, Grant D. and Cowan, Scott, "The Paradox of Privacy: Revisiting a Core Library Value in an Age of Big Data and Linked Data" (2016). FIMS Publications. 82.

https://ir.lib.uwo.ca/fimspub/82 


\section{PROJECT MUSE}

The Paradox of Privacy: Revisiting a Core Library Value in an Age of Big Data and Linked Data

D. Grant Campbell, Scott R. Cowan

The

Johns

Hopkins

University

Press

Published by Johns Hopkins University Press

DOI: https://doi.org/10.1353/lib.2016.0006

$\Rightarrow$ For additional information about this article https://muse.jhu.edu/article/613920 


\title{
The Paradox of Privacy: Revisiting a Core Library Value in an Age of Big Data and Linked Data
}

\author{
D. Grant Campbell and Scott R. Cowan
}

\begin{abstract}
Protecting user privacy and confidentiality is fundamental to the ethics and practice of librarianship, and such protection constitutes one of eleven values in the American Library Association's "Core Values of Librarianship" (2004). This paper addresses the concerns of protecting privacy in the library as they relate to library users who are defining, exploring, and negotiating their sexual identities with the help of the library's information, programming, and physical facilities. In so doing, we enlist the aid of Garret Keizer, who, in Privacy (2012), articulates a fresh theory of the concept in light of American social life in the twenty-first century. Using Keizer's theory, we examine these concerns within the context of the rise of big data systems and social media on the one hand, and linked data and new cataloging standards on the other. In so doing, we suggest that linked data technologies, with their ability to lead searchers through selfdirected, open inquiry, are superior to big data technologies in the navigation of the paradox between openness and secrecy. In this way they offer a greater potential to support the needs of queer library users: lesbian, gay, bisexual, transgendered, or questioning (LGBTQ).
\end{abstract}

\section{INTRODUCTION}

Privacy, as framed by the American Library Association (ALA), is an ideal wrapped in a paradox. The ALA Policy Manual defines Privacy as "the right to open inquiry without having the subject of one's interest examined or scrutinized by others" (American LibraryAssociation Council, 2013, p. B13). "Open inquiry," it seems, requires at least a few closed doors; only by protecting our secrets can we achieve the freedom to follow information wherever it takes us. In this paper we will place this paradox alongside 
two similar paradoxes. First, queer individuals and communities tread a fine line between secrecy and disclosure; growing visibility, prominence, and social acceptance are counterbalanced in the same environment with instances of privacy violations resulting in ruined and lost lives. Second, the emerging big data infrastructure of targeted advertising draws significance out of triviality: predictive analytics use seemingly innocuous gestures of self-disclosure to derive invasive secrets about individuals.

Libraries have embraced social networks as a means of promoting library services across a wider potential user base. But the privacy implications of society's widening range of social networks, particularly in relation to information users who belong to gender and sexual minorities, demand that we revitalize the Core Value of Privacy as enshrined in the ALA's "Core Values of Librarianship." What does it mean, today, to have the right to open inquiry without one's interest examined or scrutinized by others? What systems can libraries use to protect that right, particularly for LGBTQ users? Addressing these questions, this paper makes two modest, though significant, suggestions. First, it suggests that libraries could benefit by continued refinement of the ALA's Core Value of Privacy, placing it within a growing discourse about privacy beyond libraries in order to reinterpret it afresh for our new technological environments. Second, we argue that linked data systems rather than big data systems provide the best means of preserving and mobilizing the library community's commitment to privacy in these new environments.

\section{PRIVACY IN LIBRARIANSHIP}

According to the ALA's "Core Values of Librarianship" (2004), "protecting user privacy and confidentiality is necessary for intellectual freedom and fundamental to the ethics and practice of librarianship" (n.p.). This value emerges from the Association's "Library Bill of Rights" (1996), with its insistence on resisting censorship and the abridgement of free expression, together with its expressed commitment to providing materials to all users and presenting all points of view on a subject. The ALA Council's interpretation of the "Library Bill of Rights" argues that confidentiality exists when the library possesses identifiable information about its users and keeps that information confidential on their behalf; violation of confidentiality has a "chilling effect" on user choices (2002, p. 1).

Privacy, then, exists at the juncture between the user and the information used. Free and untrammelled exploration of the library's information resources can only take place if users are free from showing others what they are reading and having to explain why and users need not fear that the information they use will enable others to identify them. This conception of Privacy roughly aligns with a distinction articulated by Terence Craig and Mary Ludloff (2011) between privacy of behavior and communication (our right not to disclose what we do and what we say) and privacy of 
person ("our right to remain relatively anonymous in society if we choose") (p. 15). The ALA's Core Values place Privacy at the intersection of behavior and identity: only in a state of privacy can we develop and articulate a healthy relationship between what we are and what we do.

\section{LGBTQ Communities ANd the Need for Privacy}

There are many challenges that LGBTQ people face, both within their families and society in general, that contribute to the difficulty of understanding and accepting their own sexuality and in turn choosing to disclose such information to anyone. Stigmatization at both the cultural and social levels creates challenges for LGBTQ people in core aspects of human development, such as the development of personal identity within their families, development of intimate relationships, and creation of a sense of community within a larger culture (D'Augelli, Hershberger, \& Pilkington, 1998). LGBTQ people form their sexual identity, and much of their complete self-identity, through the disclosure of their sexuality. This process of disclosure, or "coming out," however, is one of the most stressful processes for an LGBTQ person because it is fraught with the risk of harassment and victimization (Bregman, Malik, Page, Makyen, \& Lindahl, 2013; Hershberger, Pilkington, \& D'Augelli, 1997; Ryan, Legate, \& Weinstein, 2015). Several studies have shown that young LGBTQ individuals are at a higher risk for bullying, violence, and verbal and physical sexual harassment (Coker, Austin, \& Schuster, 2010; DuRant, Krowchuk, \& Sinal, 1998; Saewyc, 2011; Williams, Connolly, Pepler, \& Craig, 2003). LGBTQ people are aware of the social stigmatization, negative stereotypes, and victimization that exist surrounding their sexuality and can anticipate the negative consequences of disclosure (Ryan et al., 2015). For this reason they are exposed to higher levels of unpredictable, episodic, and day-today social stress than their heterosexual peers (Mays \& Cochran, 2001). Consequently, LGBTQ people hold, and are instilled with, a fear of disclosure, questioning, or seeking any form of information; they internalize this fear and can become isolated without the proper assistance and information, which puts them at a higher risk for issues surrounding mental health, eating disorders, substance abuse, and suicide (D'Augelli, 2002). As William Ryan, Nicole Legate, and Netta Weinstein (2015) summarize, secrets, such as one's sexuality, are often kept for protection, but by doing so they perpetuate shame and guilt, which negatively impacts one's mental and physical health.

In September 2010, the world received a vivid demonstration of the ruinous effects of victimization and social stigmatization, particularly when linked to the powers of new media technologies. Tyler Clementi, a gifted 18-year-old violinist, committed suicide by jumping off the George Washington Bridge in New York City after his roommate posted videos online showing Clementi having sex with another man (Pilkington, 2010). In 
the wake of the tragedy, the Clementi family created the Tyler Clementi Foundation, devoted to the promotion of safe, inclusive spaces for LGBTQ youth and to educational partnerships, public dialogues, and awareness programs (Tyler Clementi Foundation, 2014).

Hallie Bregman, Nenna Malik, Matthew Page, Emily Makyen, and Kristin Lindahl (2013) found that when youth felt supported and had assistance with solving problems related to their sexual orientation, they were more likely to feel positive about their own identity. This brings into question how LGBTQ people can be effectively supported with answers to their questions and have their information needs met in order to form such a positive identity.

Information services in general, and libraries in particular, potentially have an important role in meliorating the stress of stigmatization and potential victimization. Reading research has shown that information and reading are very important in the articulation of identities, particularly at formative stages (McCarthey, 2001). Identity formation in general involves the process of comparison: we construct our identities "in relation to others' perceptions" (McCarthey \& Moje, 2002, p. 231). Therefore reading and literacy are important means of connecting with other perceptions beyond those we encounter in our daily lives and specific human communities. Attitudes to literacy, reading, and culture are closely connected with ethnic and cultural contexts; at the same time, exposure to literature and opportunities for reading have a profound effect on the individual's identity as a member of that ethnic or cultural group. Theorists in literacy and instruction argue that identity formation is closely linked to textual and literary practices, and in particular to the ability of readers to identify with characters and events in what they read (McCarthey \& Moje, 2002).

While few would debate the beneficial effects of reading, libraries face many challenges beyond merely making reading materials available through their collections. Many voices in the areas of gender studies, queer theory, and critical literacy argue persuasively that the task of supplying information users with good material carries hidden complexities. Theorists of critical literacy, for instance, argue eloquently for reading practices that foster freedom and alleviate human suffering (Hagood, 2002). However, the formation of an identity that is liberating and self-healing is by no means an obvious process: "Identity envisaged by some researchers interested in critical literacy ... is fragmented rather than holisitic, changing across time and space, and multiple rather than singular and autonomous. The fragmentation of identity occurs according to contextual situations with the possibility of multiple identities playing out in some institutional milieu" (p. 250).

If, as critical literacy theorists argue, identity is fragmented, multiple, and situated in paradoxical or incongruous social contexts, LGBTQ information users and the libraries that attempt to support them face chal- 
lenging tasks that involve complex negotiation. For example, our labels of self-definition—straight, gay, lesbian, transgender, bisexual-are far from being simple "yes/no" binarisms, nor do they merely express inner states regardless of social context. Frank Browning (1998) argues that what Americans call "gay identity" is in fact a complex response to a specific social context defined by urban displacement:

Having sacrificed the sure rituals of local community life for the lures, opportunities, and individual mobility offered by the modern city, we find ourselves in a social geography where we label and map our internal psychological identities and then go about the self-conscious enterprise of constructing temporary public communities based on those accumulated personal identities; to wit, the organized gay worlds of the Castro, Provincetown, Chelsea, Newtown, Midtown, [and] South Beach. (p. 27)

Browning suggests that the voices of openly queer communities could be no less disturbing, or even coercive, than the voices of older and more entrenched traditions. Indeed, at least one study of readers in LGBTQinclusive groups has suggested that homonormativity needs to be interrogated just as closely as heteronormativity (Blackburn \& Clark, 2011). While supporting the exploration and identity formation of LGBTQ users is a worthwhile task, it is neither an easy nor a transparent one. Furthermore, such a task requires a compassionate respect for each individual's need to decide on and control the timing and degree of his or her public exposure and self-revelation. And here, the ALA's paradox of Privacy becomes crucial: open inquiry requires the protection of secrets.

\section{The Need for Privacy}

The timing, approach, and needs of persons "coming out" varies greatly. A 1998 study by Anthony D’Augelli, Scott Hershberger, and Neil Pilkington indicated that, on average, young people were aware of their sexuality by age 10, labeled themselves at age 14, and told someone for the first time between ages 16-18. The average for these young people was six to eight years of uncertainty before they were able to trust and tell someone. This time between awareness and disclosure demonstrates the severity and intensity of the conflict of whether or not to come out or disclose (p. 368). Avoidance in disclosure is used because it seems like the safer and simpler path to follow. Disclosure carries significant risk, and if even the most well-meaning gay communities are prone to prejudice and coercion, as Browning (1998) suggests, youth need the chance to educate themselves and find their own optimal time and place for the necessary disclosures. It is here where it becomes evident that queer youth live their own paradox: they need secrecy, even as they need to disclose. While disclosure can be dangerous, coming out has many positive benefits for physical and mental health (Eliason \& Schope, 2001). 


\section{The Need for Inquiry}

While looking at the information needs of LGBTQ patrons, Judah Hamer (2003) found that information addressing the disclosure of one's sexual orientation was most frequently desired. Other desired material included same-sex relationships, safer-sex guidelines, and questions about gay identity as it related to romantic, familial, or platonic relationships. LGBTQ patrons are searching for material that they can relate to and identify with in the form of books, media, and magazines. It is important for these patrons to have materials that reflect their life and experiences, rather than material that comes across as "textbook" or "clinical" (Hamer, 2003; Stenback \& Schrader, 1999).

For LGBTQ youth there is no other clear place to go for information. Bharat Mehra and Donna Braquet (2006) report on the idea of LGBTQ persons being part of a "hidden minority" that do not have parents to rely upon for discussion with regards to their personal journey of coming out or coping skills for dealing with discrimination or intolerance, unlike racial minorities. An LGBTQ person may be the lone LGBTQ person within their family, and even experience violence or discrimination from their family (Bregman et al., 2013; D'Augelli et al., 1998; Mehra \& Braquet, 2006; Saewyc, 2011).

Libraries, as hubs of information, do have the potential to play a vital role in disseminating valuable information and offering support to the LGBTQ population. In her article "If I Ask, Will They Answer? Evaluating Public Library Reference Service to Gay and Lesbian Youth," Ann Curry (2005) quotes the "Library" entry from Cassell's Queer Companion: A Dictionary of Lesbian and Gay Life and Culture:

One of the main sites of self-discovery for lesbians and gay men, usu-
ally through the books but sometimes (mainly for gay men) through
the washrooms. Many of us, particularly in the dark days before the
Stonewall riot, remember going in to libraries to check for references
that would give some validity to the vague stirrings inside us we knew
marked us out as different. Starting with dictionaries, where we could
check the words we were beginning to learn, we could go on to other
works to find images or descriptions of others like us. Often such a
search has been depressing, and sometimes the only books which even
touch upon same-sex eroticism are those which exist to warn us off it,
but the mere act of looking serves as a catalyst for the formation of
identity. (p. 65)

Curry also references several sources that demonstrate how the library is the first or second important source of information for LGBTQ persons searching both for information and for confirmation that they are not alone. There are both need and potential for libraries to provide a safe place for open inquiry by LGBTQ communities. 


\section{The Need for Privacy within Inquiry}

There is a clear need and desire for information, resources, and material that serve the LGBTQ community, as well as a safe space in which to access these. However, several studies have raised concerns about the library as provider of these resources and space. Members of the LGBTQ community express that they are not always comfortable visiting libraries and checking out material due to homophobic or judgmental reactions and comments from librarians and library staff who assist them in locating or checking out materials (Cruz \& Huber, 2000; Hamer, 2003; Mathson \& Hancks, 2008; Stenback \& Schrader, 1999). In some instances, patrons need to request particular materials or are restricted in using specific materials within the library (for example, youth materials). Such policies add to the barriers to privacy that patrons experience (Mathson \& Hancks, 2008). In the aforementioned article by Curry (2005), she also references the dissertation by Steven Joyce, which notes that many youth still living at home "may be reluctant to access such information on home computers, and therefore the public library could and should provide the anonymity and safety necessary for such Internet searches" (Joyce, qtd. in Curry, p. 66).

Fear of having their sexuality or questions disclosed, either directly or implied, from having their information need known, is a large deterrent for LGBTQ people in utilizing the library. Patrons do not want to be labeled or "outed" unintentionally (Hamer, 2003). Whether it is published literature, including fiction and nonfiction books, magazines, media sources, "gray literature," or something else, libraries should be doing more to ensure that information is available to LGBTQ people in a safe and confidential environment. A study at Central Michigan University by Stephanie Mathson and Jeffrey Hancks (2008) provides a concrete example of the way in which patrons value controlling the disclosure of their library transactions. The authors write that a 20 percent increase in the circulation of LGBTQ material was noted when users were afforded the privacy of using a self-checkout system.

Libraries, then, have historically had mixed success when dealing with the privacy issues surrounding LGBTQ youth and the formation and exploration of LGBTQ identity. While the principle of open inquiry founded on respect for privacy continues to be pressingly relevant, the very logistics of managing library systems and collections, particularly in small communities, prevents libraries from doing complete justice to that principle. Libraries are discovering that respecting the privacy of LGBTQ users is a complex and politically fraught issue, divided between depictions of liberty as the product of honesty, openness, and announcement, and of liberty as the preservation of private discursive spaces that are out of the public eye. Even as library collections are enhanced to meet the growing needs 
and growing visibility of queer communities, libraries continue to find that collection development, reference and reader's advisory services, library programming, and user record maintenance must account for widely varying preferences in terms of visibility and openness. Furthermore, as collections go increasingly online, and as crowdsourcing techniques such as user tagging and commentary become more common, and as libraries move further into social-media environments, privacy and confidentiality must be negotiated in new and complex information contexts.

\section{The Challenge of New Technologies}

Queer communities are experiencing privacy issues in new and more diverse ways thanks to the new wave of networked communications afforded, not just via the internet, but through mobile computing. Within this new environment, we can find ways in which technology has both created positive and negative experiences for the LGBTQ community. First and more positively, social media has played an important role in the increasing visibility of LGBTQ individuals, through such initiatives as the "It Gets Better" project by gay activist and author Dan Savage. The YouTube-based project's goal is to inspire LGBTQ youth with positive stories by LGBTQ adults who were victimized or contemplated suicide in their youth but experienced dramatic improvement in their lives as they grew older. The project has received more than 50,000 video submissions and drawn supporters and submissions from individuals such as Barack Obama, various celebrities, and staff members of major corporations, such as Facebook and Google (Birkett, Newcomb, \& Mustanski, 2014). Such projects have a potentially revolutionary effect, by both raising public awareness of bullying and discrimination against queer youth and providing desperately needed voices, stories, and role models that enable queer youth to develop and define their own identities. This is one case where the paradox of privacy and openness works in a beneficial way: older individuals who have attained the security necessary to live openly now have a forum for imparting their insights and experiences to those who cannot yet afford such overt declarations.

Second, and perhaps more ominously, are big-data initiatives, which threaten to use personal information and internet-based activities for unintended uses. Big data is a term used to describe the vast amount of structured and unstructured data now being produced at a blistering pace that has the potential to be mined for information. Network data, as used and exploited in web-browsing behavior, e-mail, social-media sites, instant messaging, and VoIP (Voice over Internet Protocol), can be subjected to the classification models of predictive analytics and thus enable systems to detect the sexual orientation of individuals by virtue of their relationships with others (Jernigan \& Mistree, 2009). Of particular interest here 
is the data related to advertising and internet use that enable information systems, and users monitoring an individual's use of such systems, to determine or infer sexual preference.

Such systems invert the paradox that provided the foundation for the ALA's Core Value of Privacy. If open inquiry requires the protection of secrets, big-data systems work on an opposite principle: they support incidental discovery rather than deliberate and purposeful information behavior, hence surprising people into recognition rather than enabling them to ask questions and find the answers. And they do so in a fashion that often invades the individual's privacy and reveals their inmost secrets. The Tyler Clementi case provides a vivid example of how petty surveillance can go viral and in so doing destroy the necessary privacy of self-discovery.

Thus libraries face an age-old set of privacy challenges in a new technological environment. How can they best support the information needs and activities of users who are minoritized by their sexual identities? How can they support such needs and activities in a way that respects and ensures their privacy?

\section{Privacy Revisited}

In formulating strategies and making decisions, libraries might derive some benefit from a short though heartfelt addition to Picador's Big Ideas/Small Books series: Privacy (2012), an extended essay on the subject by the well-known American essayist and theologian Garrett Keizer. Keizer's treatment of privacy arises from a conviction similar to those of critical literacy theorists: that social ills will never be cured "so long as we settle for anything less than a beloved community, with liberty and justice for all" (p. 3). Rooted in thoughtful readings of various prominent privacy cases, particularly that of Tyler Clementi, Keizer attempts to formulate a definition of privacy that, while neither complete nor airtight, does justice to the human needs that lie behind the calls for privacy. In so doing, he offers three suggestions that have particular relevance to LGBTQ information users in libraries.

First, Keizer defines privacy as "a creaturely resistance to being used against one's will” (p. 20). Such uses of a person, particularly through the capture and transmission of personal information, can vary-for entertainment, convenience, or revenge, say-but the more intangible the use, the greater the sense of outrage. Furthermore, the person need not be aware of the exploitation for that exploitation to exist. By defining the breach of privacy in this way, Keizer effectively repositions the debate away from specific systems, states of being, and specific rationales. Privacy does not depend on being online or offline, nor is it about being alone rather than in company-noble reasons for breaching privacy make no difference. The right to privacy, for Keizer, lies in the freedom from being used. If we adopt his view, the ALA's conception of confidentiality acquires a 
new significance. Surveillance-monitoring what people are reading and sharing private information about them-becomes a form of using other people, even if it registers only as a disapproving frown and a shake of the head at the checkout desk.

Second, privacy, as an operationalized concept, consists not simply of solitude or invisibility but an individual's power to modulate the extent of his or her self-revelation in specific circumstances. Citing W. H. Auden, Keizer defines humanity as a "capacity for self-disclosure" (p. 37). While an animal is unable either to hide or articulate anything, human beings have the capacity to fully disclose or hide what they choose and to hide what they choose (Keizer, 2012). Surveillance therefore is a deeply dehumanizing experience not just because it is covert and manipulative but because it removes a person's power to choose the nature and degree of self-revelation.

Finally, privacy can have a paradoxical relation to the public sphere. Keizer suggests that individuals frequently move into the public sphere, not to sacrifice their privacy, but to retain it. In his analysis of a court decision that grappled with the question of privacy in public places, Keizer writes:

[The decision] fails to take into account ... the number of people whose very act of stepping out the front door represents a "subjective expectation of privacy"-because the public sphere is the only place where they can have a reasonable hope of finding it. As the nineteenthcentury feminist Charlotte Gilman Perkins testily observed, "The home is the one place on earth where no one of the component individuals can have any privacy.” (pp. 25-26)

The public sphere may well be the most important factor in an individual's quest to use information sources to explore and articulate a sexual identity with a reasonable expectation of privacy. The library occupies a position of significant though paradoxical importance: its status as a public place makes it an ideal place in which to experience genuine privacy. In this context, "open inquiry," as the ALA puts it, consists of the freedom to inquire, unrestricted by familial, communal, or tribal obligations. Such openness, Keizer suggests, can only be achieved in the privacy of the public sphere.

If then we apply these three premises to the discussion of LGBTQ users and their freedom to explore their gender and sexual identities in privacy, we find that

- information use is not merely the process of becoming informed but is an exercise of the will, an exercise which may enact self-determination but also may enact the domination, control, and abuse of others;

- queer users enact seemingly paradoxical impulses toward both secrecy and self-revelation; identify formation requires the gradual evolution of an ability to modulate and control one's own revelations; and 
- the library's very status as a public place is an important part of its role in the formation of this identity.

Through this lens, we can assume that queer library users are using the library as a safe place within the public sphere to locate and use information that supports self-motivated explorations of gender and sexual identity. And the evidence in library science research suggests that this is a complex and ambiguous process, which is only partially supported by our current infrastructure. Not only are many library systems providing inadequate staff training to support sexual minorities (Goldthorp, 2007), but our very infrastructure of information organization sometimes resists such exploration.

Formal classification systems, for instance, suffer from their allegiances to a print-based shelf-order system that requires that each item occupy only one physical place at a time. Interviews with gay and lesbian information users suggest that queer information users classify information differently in different situations (Campbell, 2004). At times, users place sexual orientation at the forefront of the facet order, seeking out information spaces in which the queer materials are separated off from the other materials; at other times, these same users move sexual orientation further back, seeking environments in which materials that appeal to gay or lesbian readers are integrated into broader categories, thereby showing continuities, and preventing a "ghetto" effect. Subject access is frequently undermined by entrenched biases, inherited from a tradition of describing same-sex attraction as "perverse" or "deviant" behavior (Adler, 2013, p. 309). And even at its best, subject analysis enabled by traditional indexing tools is troubled by unresolved distinctions between what Eve Sedgwick (1990) describes as minoritizing and universalizing views: queerness as the lifestyle of a minority community, and queerness as a concept with universal implications for everyone, regardless of their sexual orientation (see also Campbell, 2013).

Given these problems, what possible solutions suggest themselves? And how might big data and linked data contribute to those solutions?

\section{Big Data And Social Media}

A survey by Library Journal found that 86 percent of libraries are using social media (Dowd, 2013). During tough economic times and severe budget cuts, social media provides free marketing and communication tools for the library (Dankowski, 2013) and helps them to stay relevant to their users, as 67 percent of Americans ages 12 and older use some form of social media. Libraries are embracing the value of social media as a means to connect to their users and respond to user needs (King, 2015a). Not only can the library advertise upcoming events using different socialmedia platforms, but they can advertise new acquisitions and services, 
such as the ability to download the newest album by using software available from the library (King, 2015b, p. 10). Libraries are using social-media platforms such as Facebook, Twitter, YouTube, Pinterest, Vine, Instagram, Tumblr, and Snapchat to appeal to all users. However, many libraries have also branched out to using LinkedIn to appeal to the professional crowd and connect users for job and work leads (King, 2015b). LinkedIn could potentially be used by the library to connect to the business community for finance-related issues and to provide opportunities for fundraising. All of these social-media platforms are a way of connecting the library to its users, but they also have the potential for other, less than ideal effects. Participation in social media, along with other forms of web usage, such as search engines and e-commerce services, transforms us from users of information into sources of information. In big-data systems, we become the objects of scrutiny, assessment, and prediction.

Big data has much to offer users who are exploring gender and sexual identities. The predictive analytics that lie behind targeted advertising also play a part in recommender systems. By analyzing both explicit user gestures, in the form of ranking, and liking, and commenting, and implicit user behavior, in the form of search queries, browsing behavior, and buying decisions, recommender systems, whether collaborative or contentbased, are able to predict a user's tastes and prompt the user with materials on the basis of those predictions. What is more, the predictions enable sites like Netflix to quietly become aligned around a user's individual tastes, where desirable options cluster more closely. Indeed, the longer we use services like Netflix and YouTube, the more the interface comes to reflect our preferences, just as the ads on Google mysteriously conform to our query histories and geographical locations. The effect of this prediction is often to cause a digital environment to become a reflection of an individual's tastes, not all of which may have been voluntarily expressed. Therefore if the predictions are accurate, they could give that individual the chance of watching an identity emerge, partly in response to explicit desires and partly in response to implicit ones-possibly even unacknowledged curiosities and needs.

Despite these significant potential advantages, the nature of big-data analytics flies in the face of Keizer's (2012) definition of privacy, simply because the predictions of such analytics are ultimately concerned with measuring — not information, but users. Big data works not by answering our questions but by tracking our behavior: "By giving out our information for the convenience of products and services, we have also opened the door to far more intrusive monitoring by government agencies in the name of national, state, and local security. How we reached this point is the result of technological innovation and entrepreneurship" (Craig \& Ludloff, 2011, p. 2). While social media may have tremendous uses in promoting libraries and library programming in youth communities, the 
big-data implications that lie behind the active use of social media suggest that libraries should exercise caution and vigilance when integrating it into information services for gender and sexual minorities.

\section{Linked Data And New Cataloging Standards}

Against the prominence of big data and its associated practices of crowdsourcing through user tagging, we are also witnessing a less prominent though equally important set of emergences, both within libraries and in web-based information systems. First, the "Anglo-American Cataloging Rules" are gradually giving way to the new standard of bibliographic description: "Resource Description and Access" (RDA). This new standard remains controversial, and the library community has yet to implement it completely, partly because its full potential will not be realized until the Library of Congress's MARC formats are replaced by a more adaptable and flexible encoding system. Nonetheless, RDA significantly enhances a cataloger's power to encode and display bibliographic relationships through its extensive list of relationship designators. By facilitating rich relationships, RDA offers the potential to link library catalogs to the standards of linked data emerging through the Semantic Web initiative, led by the World Wide Web Consortium. The advantages of RDA include the following:

- Unlike big data, linked data has a much closer link with traditional library cataloging. Libraries have been heavily involved in metadata schemes since the Dublin Core, and linked data projects, such as metadata schemes, emerge from a similar conviction, first expressed by Clifford Lynch in 1997 (p. 52), that the internet would need the skills of computer scientists, allied to those of librarians. Linked data projects, the latest manifestation of the Semantic Web, work to embed meaningful relationships in a purposeful way, thus enabling connections that reflect some level of systematic thought and consensus within and among domains of knowledge. The Semantic Web, positioned as it is between the traditional but unwieldy practice of information description in libraries and the impressive but unpredictable advancements of big data, offers a chance for knowledgeable experts to make their expertise accessible in ways that, hopefully, will do justice to the complexity of the information and the needs of end users. The standards of what has come to be called "linked data"-particularly the Resource Description Framework $(\mathrm{RDF})$ and the Working Ontology Language (OWL) - predate the web 2.0, big data, and much social media, and are founded on a principle of information management specifically designed to achieve two goals: to make electronic data machine-understandable, as well as machinereadable, by encoding it according to standards defined by learned communities within various domains; and enabling web agents to perform operations of evaluation, retrieval, organization, and linking based on logical inference. 
- To organize the understanding of various knowledge domains into machine-readable ontologies that simultaneously enable web systems to establish stable namespaces, while at the same time facilitating communication across these namespaces through careful crosswalk design.

Early visions of the Semantic Web sounded much like today's visions of big data. Tim Berners-Lee, James Hendler, and Ora Lassila (2001) imagined an environment of intelligent agents that learned from their users and the web and that prompted busy human beings with suggestions, alternatives, and labor- and time-saving devices. Nonetheless, the Semantic Web works on significantly different principles. Linked data systems emerging from the Semantic Web remain focused on the information structures, rather than on the users; in this sense, the Semantic Web is not about users, but about knowledge domains. The ontologies that it strives to create are based on the key relationships that exist within a particular subject or field, as well as on the questions that users within that field can be expected to ask. Its many standards aim to capture the implicit and explicit knowledge structures that imbue specialized knowledge areas, and to make those structures machine-readable for purposes of retrieving and organizing information on the basis of those structures. As a result, linked data rests on an empowering vision of synthesizing and delivering information in the service of a conscious inquiry.

We have, then, a new library cataloging standard-RDA-which gives greater support to describing and encoding bibliographic relationships. We have big-data systems making significant inroads into all our daily lives. And we have linked data systems slowly growing in certain areas of networked information culture. How best can libraries assist sexual minorities in their information needs and explorations while enabling them to hide, as much as they wish to hide, within the plain sight of the public sphere?

\section{Proposed Solutions}

\section{Steady as She Goes}

Before we contemplate massive changes through new and innovative technologies, we should consider one possibility: keep doing what we are doing, and just try to do it a little better. The ALA's Core Value of Privacy rests on an assumption that continues to be valid: namely, that by exercising up-to-date collection management and accurate and effective bibliographic control, we empower users to locate information with a minimum of interference.

Queer information users, particularly those looking for representations of themselves and their situations, frequently make use of formal and informal reading suggestions. LGBTQ discussion groups, of the sort run by Mollie Blackburn and Caroline Clark (2011), generate reading lists for circulation among members; some of these lists are expanded with commentaries and then published (Drake, 1998). Even passing refer- 
ences are noted and later pursued; as one participant of an earlier study commented, "You're always looking for the smoke" (Campbell, 2004, p. 111). Library catalogs therefore have served LGBTQ users for years by offering accurate, precise, and informative bibliographic descriptions, coupled with effective and reliable authority control, thereby enabling users to identify and locate known items. Libraries can and should continue to use published lists of popular and useful materials as guides to acquisition, and to catalog them completely and accurately so that users can locate them easily. This is hardly a glamorous activity, but we should note and respect its ongoing importance.

In addition, library catalogs could also do more to facilitate the long tradition in queer publishing of writing in series. From the gay pulp fiction of the 1950s and 1960s through to modern series, queer readers have always relied upon series to find more of authors or kinds of material they like. The conscientious entry of series information, as well as publisher information, can be very useful to readers who wish to expand from their known items to others.

\section{Bibliographic Relationships}

With the advent of RDA, library catalogers now have a greater repertoire of relationships that may be defined, which could conceivably help queer users expand from what they know to what they would like to know.

Suppose, for example, a gay male reader were to somehow stumble upon the novel Further Tales of the City (1994) by Armistead Maupin, the third novel in the iconic Tales of the City series; suppose, in addition, that this was the first story to provide him with a literary character he could relate to. He would have difficulty finding the rest of the series or any related material. If the novel were published as part of a series, some catalogs may contain the series title in the 490 field of the MARC record, and an access point for the entire series in the 830 field. However, catalogers traditionally confine series statements to explicitly identified sequences within a single publishing house, rather than to thematic or conceptual sequences. In addition, catalogs may or may not provide links to the subject headings. The subject headings that are inherited through the copy-cataloging process, however, are frequently vague and unhelpful: "City and town life-Fiction and San Francisco (Calif.) - Fiction." For a gay male user, these links do not provide access to more materials related to gay fiction, gay characters, or something with which he can relate. He is then left to either continue struggling with searching on his own or divulging his information needs by requesting assistance.

Using the RDA relationship designators, which are used for broader and more diverse relationships, rather than mere publishing sequences, a user looking for a connection to related material would be able to easily locate it. Using the same example, the user would have links to the entire 
series within the library catalog, including audio and electronic versions, the television mini-series it spawned, the cast recording of the musical version, blogs, newspaper articles, and so on. A small sampling of the possible relationship designators allowed by RDA might be:

- In Series: Maupin, Armistead. Tales of the City series

- Preceded by: Maupin, Armistead. Author. Tales of the City

- Preceded by: Maupin, Armistead. Author. More Tales of the City

- Succeeded by: Maupin, Armistead. Author. Babycakes

- Adapted as television program: Further Tales of the City (mini-series DVD) Musical variations: Tales of the City Musical

These relationship designators would appear as follows in a MARC record:

Table 1. MARC record of sample relationship designators

\begin{tabular}{|c|c|c|c|}
\hline 500 & & & \$a Sequel to: Tales of the city; and More tales of the city. \\
\hline 780 & 0 & 0 & \$a Maupin, Armistead. \$t Tales of the city. \\
\hline 780 & 0 & 0 & \$a Maupin, Armistead. \$t More tales of the city. \\
\hline 785 & 0 & 0 & \$a Maupin, Armistead. \$t Babycakes \\
\hline 787 & 0 & & \$i Adapted as television program: \$a Further tales of the city (mini-series) \\
\hline 787 & 0 & & \$i Musical variations: $\$$ t Tales of the city musical \\
\hline
\end{tabular}

Using these relationship designators, we can build a larger connection to other material in which the user may be interested. Relationships formerly intimated, assumed, or accrued over time can be explicitly encoded into bibliographic records to provide networks of bibliographic relationships. Just as automated checkout caused an increase in the use of LGBTQ materials, the chance to locate materials through these enhanced relationships could increase their access and use.

\section{Linked Data Ontologies and the Expansion of Bibliographic Relationships}

If we were to take these relationships still further, we could conceivably expand traditional bibliographic relationships into something more adventurous, using linked data principles. An ontology is defined by the Semantic Web community as "an explicit and formal specification of a conceptualization" (Antoniou, Groth, van Harmelen, \& Hoekstra, 2012, p. 10). Ontologies derive from both controlled vocabularies and classification structures, but they tend to be more fluid and conditioned by specific knowledge domains and information cultures. They can be used to encode connections that a particular community finds meaningful and to make material accessible through these connections.

Sexual subcultures often make extensive use of intertextuality, in which canonical and influential works of mainstream culture undergo various processes of homage, adaptation, parody, or subversion, to create a network of relationships, which, while lying beyond RDA, could be captured and encoded. If we were to take, for instance, L. Frank Baum's The Wonder- 


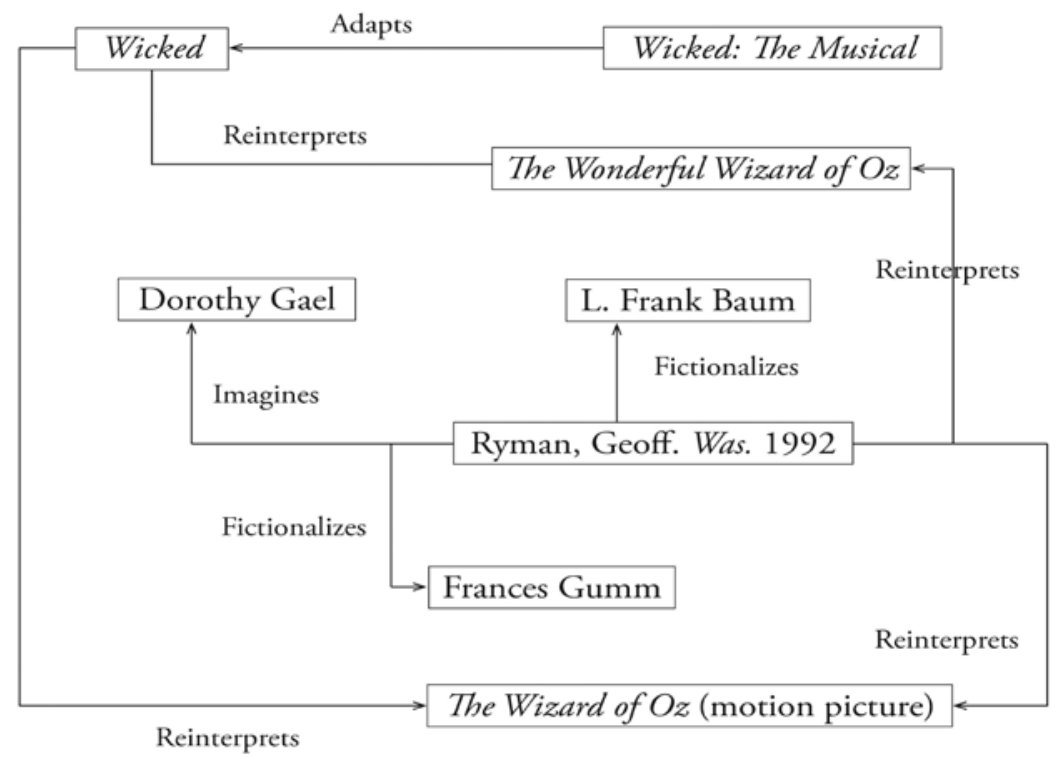

Figure 1. A web of relationships.

ful Wizard of Oz (1900), together with Geoff Ryman's Was (1992), we can use Ryman's queer homage to Baum's original story as the basis for a network of associations that have great cultural significance to many North American gay male communities (see fig. 1). Ryman's novel is a reinterpretation of both The Wonderful Wizard of $\mathrm{Oz}$ and its 1939 film adaptation, The Wizard of $O z$; in it, he fictionalizes Baum himself, and Frances Gumm, the actress who would come to star in the movie adaptation under the name of Judy Garland. He reimagines Dorothy Gale as a Kansas orphan and survivor of sexual abuse, renamed Dorothy Gael, who inspires Baum's fictional character. We could expand the network further to note that both the original novel and the movie adaptation were reimagined in Gregory Maguire's novel Wicked (1995), which was later adapted into a Broadway musical (and a new movie in the near future).

Out of all these relationships, it should be possible to identify a reasonable number of relationship types that do justice, not merely to the bibliographic nature of the materials but to the patterns of association that emerge from a community that specializes in adaptation, impersonation, parody and homage. Bibliographic records from libraries for these various materials could be linked together through an online instantiation of the ontology, thereby enabling a user, in reasonable privacy, to explore relationships that lead to fresh insights, new models of thinking and being, and enhanced models of gender and sexual identity. 


\section{Conclusion}

The ALA's choice and continued support of Privacy as a Core Value of librarianship appears both necessary and quixotic in these changing times. The painfully slow progress of the library community toward semantically rich bibliographic relationships looks incongruous next to the remarkable speed with which big-data applications are evolving and spreading into all aspects of our lives. But Keizer's (2012) thoughts on privacy serve as a sobering reminder of libraries' obligations to protect their users' privacy, particularly in information environments that favor convenience, interoperability, and instant gratification. Big-data technologies are inconsistent with a concept of privacy that rests on open inquiry in an environment of safety and freedom from surveillance. The slower, less glamorous protocols that emerge from bibliographic description, together with the quiet potential of linked data ontologies, are more consistent with Keizer's vision of a beloved community with liberty and justice for all. And the concept of liberty and justice for all remains an enduringly relevant goal for libraries and an enduring foundation of the ALA's Core Values.

\section{REFERENCES}

Adler, M. (2013). Paraphilias: The perversion of meaning in the Library of Congress catalog. In P. Keilty \& R. Dean (Eds.), Feminist and queer information studies reader (pp. 309-323). Sacramento, CA: Litwin.

American Library Association (ALA). (1996). Library bill of rights. Retrieved from http:// www.ala.org/advocacy/intfreedom/librarybill

American Library Association (ALA). (2002). Privacy: An interpretation of the library bill of rights, 2001-2002 CD\#19.5. Retrieved from http://www.ala.org/aboutala/sites/ala .org.aboutala/files/content/governance/policymanual/updatedpolicymanual/ocrpdfof prm/53-1-16privacy.pdf

American Library Association (ALA). (2004). Core values of librarianship. Retrieved from http://www.ala.org/advocacy/intfreedom/statementspols/corevalues\#privacy

American Library Association (ALA) Council. (2013). ALA policy manual. Retrieved from http://www.ala.org/aboutala/governance/policymanual

Antoniou, G., Groth, P., van Harmelen, F., \& Hoekstra, R. (2012). A Semantic Web primer. Cambridge, MA: MIT Press.

Berners-Lee, T., Hendler, J., \& Lassila, O. (2001). The Semantic Web. Scientific American, 284(5), 34-43.

Birkett, M., Newcomb, M. E., \& Mustanski, B. (2014). Does it get better? A longitudinal analysis of psychological distress and victimization in lesbian, gay, bisexual, transgender, and questioning youth. Journal of Adolescent Health, 56(3), 280-285.

Blackburn, M. V., \& Clark, C. T. (2011). Analyzing talk in a long-term literature discussion group: Ways of operating within LGBT-inclusive and queer discourses. Reading Research Quarterly, 46(3), 222-248.

Bregman, H. R., Malik, N. M., Page, M. J. L., Makyen, E., \& Lindahl, K. M. (2013). Identity profiles in lesbian, gay, and bisexual youth: The role of family influences. Journal of Youth and Adolescence, 42(3), 417-430.

Browning, F. (1998). A queer geography: Journeys toward a sexual self. New York: Farrar, Straus \& Giroux.

Campbell, D. G. (2004). A queer eye for the faceted guy: How a universal classification principle can be applied to a distinct subculture. In I. C. McIlwaine (Ed.), Advances in knowledge organization, Vol. 9 (pp. 109-113). Würzburg, Germany: Ergon Verlag.

Campbell, D. G. (2013). Queer theory and the creation of contextual subject access tools for gay and lesbian communities. In P. Keilty \& R. Dean (Eds.), Feminist and queer information studies reader (pp. 290-308). Sacramento, CA: Litwin. 


\section{LIBRARY TRENDS/WINTER 2016}

Coker, T. R., Austin, S. B., \& Schuster, M. A. (2010). The health and health care of lesbian, gay, and bisexual adolescents. Annual Review of Public Health, 31, 457-477.

Craig, T., \& Ludloff, M. E. (2011). Privacy and big data. Beijing: O'Reilly.

Cruz, J., \& Huber, J. (2000). Information needs and information-seeking behaviors of HIV positive men and women. Medical Reference Services Quarterly, 19(3), 39-48.

Curry, A. (2005). If I ask, will they answer? Evaluating public library reference service to gay and lesbian youth. Reference and User Services Quarterly, 45(1), 65-75.

Dankowski, T. (2013, May). How libraries are using social media. American Libraries. Retrieved from http://www.americanlibrariesmagazine.org/article/how-libraries-are-using-social -media

D'Augelli, A. R. (2002). Mental health problems among lesbian, gay and bisexual youths ages 14 to 21. Clinical Child Psychology and Psychiatry, 7(3), 433-456.

D’Augelli, A. R., Hershberger, S. L., \& Pilkington, N. W. (1998). Lesbian, gay, and bisexual youth and their families: Disclosure of sexual orientation and its consequences. American Journal of Orthopsychiatry, 68(3), 361-371.

Dowd, N. (2013, May 7). Social media: Libraries are posting, but is anyone listening? Library Journal. Retrieved from http://j.libraryjournal.com/2013/05/marketing/social-media -libraries-are-posting-but-is-anyone-listening

Drake, R. (1998). The gay canon: Great books every gay man should read. New York: Anchor.

DuRant, R. H., Krowchuk, D. P., \& Sinal, S. H. (1998). Victimization, use of violence, and drug use at school among male adolescents who engage in same-sex sexual behaviour. Journal of Pediatrics, 133(1), 113-118.

Eliason, M. J., \& Schope, R. (2001). Does “don't ask don't tell” apply to health care? Lesbian, gay, and bisexual people's disclosure to health care providers. Journal of the Gay and Lesbian Medical Association, 5(4), 125-134.

Goldthorp, J. D. (2007). Can Scottish public libraries claim they are socially inclusive of all minority groups when lesbian fiction is still so inaccessible? Journal of Librarianship and Information Science, 39(4), 234-248.

Hagood, M. C. (2002). Critical literacy for whom? Reading Research and Instruction, 41(3), 247-266.

Hamer, J. S. (2003). Coming-out: Gay males' information seeking. School Libraries Worldwide, 9(2), 73-89.

Hershberger, S. L., Pilkington, N. W., \& D’Augelli, A. R. (1997). Predictors of suicide attempts among gay, lesbian, and bisexual youth. Journal of Adolescent Research, 12(4), 477-497.

Jernigan, C., \& Mistree, B. F. T. (2009). Gaydar: Facebook friendships expose sexual orientation. First Monday, 14(10). Retrieved from http://firstmonday.org/ojs/index.php/fm /article/view/2611/2302

Keizer, G. (2012). Privacy. New York: Picador.

King, D. L. (2015a). Why use social media? Library Technology Reports, 51(1), 6-9.

King, D. L. (2015b). Landscape of social media for libraries. Library Technology Reports, 51(1), $10-15$.

Lynch, C. A. (1997). Searching the internet. Scientific American, 276(3), 52-56.

Mathson, S., \& Hancks, J. (2008). Privacy please? A comparison between self-checkout and book checkout desk circulation rates for LGBT and other books. Journal of Access Services, 4(3), 27-37.

Mays, V. M., \& Cochran, S. D. (2001). Mental health correlates of perceived discrimination among lesbian, gay, and bisexual adults in the United States. American Journal of Public Health, 91(11), 1869-1876.

McCarthey, S. J. (2001). Identity construction in elementary readers and writers. Reading Research Quarterly, 36(2), 122-151.

McCarthey, S. J., \& Moje, E. B. (2002). Identity matters. Reading Research Quarterly, 37(2), 228-238.

Mehra, B., \& Braquet, D. (2006). A “queer" manifesto of interventions for libraries to "come out" of the closet! A study of "queer" youth experiences during the coming out process. Library and Information Science Research Electronic Journal, 16(1), 23-51.

Pilkington, E. (2010, September 30). Tyler Clementi, student outed as gay on internet, jumps to his death. Guardian. Retrieved from http://www.theguardian.com/world/2010/sep/30 /tyler-clementi-gay-student-suicide 
Ryan, W. S., Legate, N., \& Weinstein, N. (2015). Coming out as lesbian, gay, or bisexual: The lasting impact of initial disclosure experiences. Self and Identity, 14(5), 549-569.

Saewyc, E. M. (2011). Research on adolescent sexual orientation: Development, health disparities, stigma, and resilience. Journal of Research on Adolescence, 21(1), 256-272.

Sedgwick, E. K. (1990). Epistemology of the closet. Berkeley: University of California Press.

Stenback, T., \& Schrader, A. (1999). Venturing from the closet: A qualitative study of the information needs of lesbians. Public Library Quarterly, 17(3), 37-50.

Tyler Clementi Foundation. (2014). The Tyler Clementi Foundation. Retrieved July 16, 2015, from http://www.tylerclementi.org

Williams, T., Connolly, J., Pepler, D., \& Craig, W. (2003). Questioning and sexual minority adolescents: High school experiences of bullying, sexual harassment and physical abuse. Canadian Journal of Community Mental Health, 22(2), 47-58.

D. Grant Campbell completed his Ph.D. in English at Queen's University, Kingston, Ontario, and his Master of Information Studies at University of Toronto, and is an associate professor in the Faculty of Information and Media Studies at the University of Western Ontario. He teaches courses in bibliographic description, metadata, classification, subject analysis, critical theory, and big data. His research applies theories of information organization and the paradigms of new data standards to marginalized populations, including LGBTQ communities and individuals living with dementia.

Scott R. Cowan is an information services librarian at the University of Windsor in Windsor, Ontario. He completed his Master of Library and Information Science degree at the University of Western Ontario, and his undergraduate degrees in education and music education at the University of Saskatchewan. He is a former middle and high school teacher, and his research has focused on information literacy in postsecondary institutions, student experiences, and library services relating to marginalized communities. 